\title{
Severe Calcification of the Arteries
}

\author{
Naohiko Imai, Motonori Nagasawa and Kenjiro Kimura
}

Key words: calcification, hemodialysis, uremic milieu, atherosclerosis

(Intern Med 51: 1445, 2012)

(DOI: 10.2169/internalmedicine.51.7516)

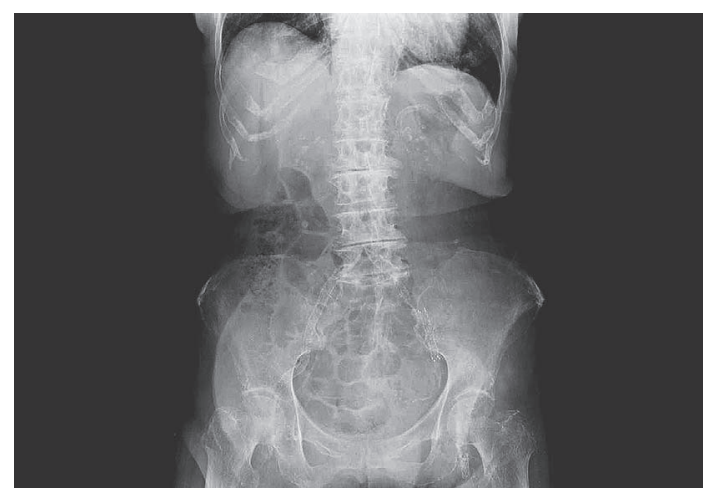

Picture 1.

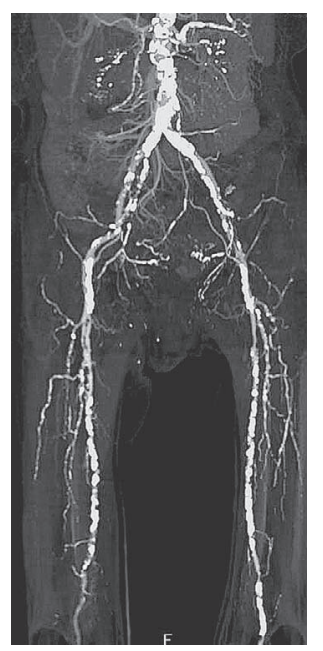

Picture 2.

An 86-year-old woman with type 2 diabetes and hypertension was admitted for the treatment of severe peripheral artery disease. She had been receiving hemodialysis for 6 years. She underwent intervention and a stent was deployed. Plain radiography of the abdomen showed marked calcification of the wall of the common iliac arteries (Picture 1) and helical computed tomography of the lower abdomen and the

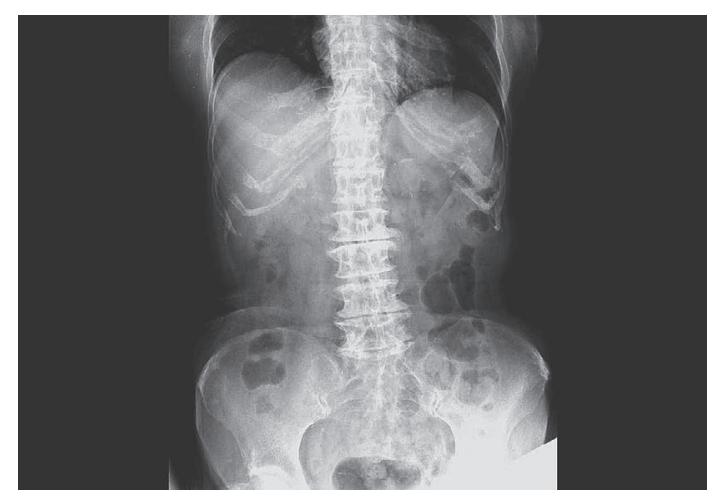

Picture 3.

legs also showed severe aortic calcification (Picture 2). There had been no calcification seen on abdominal X-rays at the initiation of dialysis (Picture 3).

Arterial calcification is common in patients with CKD, and moreover, patients on dialysis have an increased atherosclerotic burden and it often progresses over a short period of time (1). Dialysis-specific pathogenetic factors including hyperphosphatemia, high Ca X P product and elevated parathyroid hormone levels, were all unremarkable in this case and she did not require treatment with calcium-containing phosphate binders and vitamin D analogs. Traditional risk factors only partly explain the calcification that seems to be more linked to the uremic milieu and abnormalities in mineral metabolism (2). The optimal management of vascular calcification in dialysis patients remains uncertain.

The authors state that they have no Conflict of Interest (COI).

\section{References}

1. Goodman WG, London G. Vascular calcification in chronic kidney disease. Am J Kidney Dis 43: 572-579, 2004.

2. Giachelli CM. Vascular calcification mechanisms. J Am Soc Nephrol 15: 2959-2964, 2004.

St. Marianna University School of Medicine, Japan

Received for publication February 12, 2012; Accepted for publication February 19, 2012

Correspondence to Dr. Naohiko Imai, naohiko.imai@gmail.com

(C) 2012 The Japanese Society of Internal Medicine Journal Website: http://www.naika.or.jp/imindex.html 